УДК 532.529:663.14. 033:663.143.2

\title{
СРАВНЕНИЕ ЭФФЕКТИВНОСТИ АЭРАЦИИ КУЛЬТУРАЛЬНОЙ СРЕДЫ В МАССООБМЕННЫХ УСТАНОВКАХ С ДИСКРЕТНО-ИМПУЛЬСНЫМ ВВОДОМ ЭНЕРГИИ ПРИ КУЛЬТИВИРОВАНИИ ХЛЕБОПЕКАРСКИХ ДРОЖЖЕЙ
}

\author{
Долинский А.А., академик НАН Украины, Ободович А.Н., д.т.н, Фищенко А.Н., к.Т.н., \\ Сидоренко В.В.
}

Институт технической теплофизики НАН Украины, ул. Желябова, 2а, Киев, 03680, Украина

У статті представлено результати порівняння ефективності аерації культурального середовища в двох типах масообмінних установок 3 дискретно-імпульсним введенням енергіï в процесі культивуванні дріжджів Saccharomyces cerevisiae.

Библ. 11, табл. 3, рис. 3.
В статье представлены результаты сравнения эффективности аэрации культуральной среды в двух типах массообменных установок с дискретно-импульсным вводом энергии в процессе культивировании дрожжей Saccharomyces cerevisiae.
The article presents the results of comparing the efficiency of the aeration of the culture medium in the two types of mass transfer systems with discrete-pulse energy input in the process of cultivating the yeast Saccharomyces cerevisiae.

Ключевые слова: метод дискретно-импульсного ввода энергии, аэрирование, роторно-пульсационный аппарат, абсорбер, скорость массопередачи.

Из всего многообразия способов интенсификации тепломассообменных процессов в гетерогенных средах, лежащих в основе операций диспергирования, эмульгирования, растворения, катализа и др., метод дискретно-импульсного ввода энергии (ДИВЭ) занял лидирующие позиции с точки зрения отношения величины вводимой энергии к уровню достигаемого результата. Исследованию данного феномена, определению механизмов и основных закономерностей трансформации и распределения вводимой в рабочую зону реализующих метод ДИВЭ устройств энергии посвящена достаточно обширная литература. Наиболее полно результаты как теоретических, так и экспериментальных исследований данного метода изложены в [1].

Ранее авторами была поставлена серия экспериментов по аэрированию питательных и культуральных жидкостей в ферментационной установке с применением метода ДИВЭ [2,3]. Целью данных исследований было определение интенсивности абсорбции кислорода воздуха в данном процессе при изменении условий обработки, а также влияние интенсивности обработки на физиологическое состояние входящих в состав культуральной жидкости дрожжевых клеток. Ос- новным рабочим органом данной установки, в котором, собственно, реализуется метод ДИВЭ, являлся роторно-пульсационный аппарат (РПА) цилиндрического типа, пульсационный узел которого состоял из двух роторов и одного статора. Количество пазов и толщина межцилиндрового зазора варьировались. Таким образом, менялись частота пульсаций и скорость сдвига потока - основные характеристики работы РПА. Многократность обработки исследуемой среды осуществлялась за счёт рециркуляции. Подача воздуха в рабочую зону аппарата осуществлялась самовсасыванием за счёт эффекта Вентури а расходном трубопроводе.

Полученные данные позволяют уверенно говорить о том, что использование метода ДИВЭ при аэрировании культуральной жидкости в процессе культивирования дрожжей - сахаромицетов позволяет существенно сократить по сравнению с традиционными методами расход воздуха на аэрацию, а также увеличить удельную скорость роста дрожжей.

Следует, однако, отметить, что метод ДИВЭ реализуется не только в РПА. Так как метод ДИВЭ является методом комплексного воздействия на обрабатываемую среду, сочетающий в 
себе ряд физических воздействий, актуальным становится вопрос о степени влияния каждого из них на конечный результат обработки. Таким образом, получение готового продукта в каждом конкретном процессе можно обеспечивать не только за счёт повышения или понижения уровня вводимой в аппарат энергии, но и за счёт выбора конструктивных особенностей пульсационного узла, а значит - усиления механизмов ДИВЭ, наиболее эффективных для данного конкретного процесса.

Исследования по применению метода ДИВЭ в технологиях, связанных с интенсификацией процесса массообмена в системе газ - жидкость, а также разработка массообменных аппаратов проводилась в Институте технической теплофизики НАН Украины в течение многих лет. В биотехнологиях метод ДИВЭ реализовывался путём резкого сброса давления в ферментёре [4], путём применения импульсного пульсатора [5] и т.д. Наиболее близким к РПА по принципу действия, а также по назначению, является разработанный в ИТТФ, аэратор - диспергатор, используемый для аэрации водоёмов [6], основным рабочим органом которого является роторно-дисковый аппарат.

Так, исследования по дискретно-импульсной подаче газа на процесс абсорбции в экспериментальной установке с применением диспергатора представлены в [7]. Целью данной работы являлось исследование размеров образующихся в воде пузырьков воздуха в процессе барботажа путём замены постоянного расхода газа через единичное отверстие (сопло) прерывистым. Для стабилизации размеров пузырьков воздуха использовался алкилтриметиламониевый хлорид. Установка представляла собой ёмкость в днище которой располагался диспергатор, соединённый с компрессором. Диспергатор состоял из трёх перфорированных соосных дисков (двух неподвижных и одного подвижного). Средний диск приводился в движение электродвигателем. Полученные данные свидетельствовали о том, что при подаче воздуха под давлением от компрессора на выходе диспергатора образовывалось поле распределённых в жидкости мелких воздушных пузырьков или газовая эмульсия [8]. Данное дробление происходило за счёт порционной подачи газа за счёт периодически совпадающих отверстий ротора-статора. Размеры пузырьков зависели как от расхода газа, так и от размера отверстий в дисках, однако, основное влияние данный параметр оказывала частота вращения подвижного диска (ротора). Таким образом, решалась основная проблема барботажных аппаратов - создание изолированных друг от друга пузырьков воздуха субмиллиметровых размеров. Подобный приём позволил создать значительную поверхность раздела фаз.

Дальнейшие работы по применению метода ДИВЭ, реализующегося в диспергаторе, проводились в процессе насыщения жидких сред растворимым газом (сатурации) в технологии получения газированных напитков [9]. Технология и установка синхронно-смесительного типа были разработаны на основе абсорбера СА-100, действующего по принципу, описанному выше. Основное внимание авторы уделяют описанию основных диспергирующих и массообменных эффектов, которые связаны с импульсной подачей газа, созданием регулярных пульсаций давления в отверстиях дисков и образованием турбулентных струй пузырьковой газожидкостной дисперсии в потоке газируемой жидкости. Авторами установлено, что при совпадении частоты естественных колебаний объемов газа в отверстиях ротора с частотой пульсаций давления наблюдается явление резонанса, благодаря чему резко увеличивается амплитуда колебаний поверхности раздела фаз с потерей её устойчивости и, как следствие, дробление газа на микропузырьки. Коэффициент массопередачи при этом увеличивается на порядок. Определение коэффициентов массопередачи газа в жидкость рассчитывалось путём ввода понятия эквивалентного сферического пузыря (ЭП). По мнению авторов, во время пульсаций объема газа в окрестностях отверстия генерируются стационарные колебания давления определенной частоты и под их воздействием происходят колебания формы сферических пузырьков, имеющих собственную частоту колебаний. Благодаря явлению резонанса в аппарате пузырьки газа в струе не дробились, а частично растворившись в струе, распределялись в турбулентном потоке жидкости в проточной части, где полностью растворялись. 
Таким образом, применение диспергатора (абсорбера) роторно-дискового типа в позволяет решать задачи того же характера, что и РПА а именно аэрированию культуральных жидкостей в ферментационной установке методом ДИВЭ в процессе культивирования дрожжей.

Принципиальным отличием в обработке культуральной жидкости между двумя указанными аппаратами заключаются в том, что распределенные в питательной среде дрожжевые клетки не проходят через прорези роторно-дискового узла аппарата и, следовательно, не подвергаются влиянию в полной мере комплекса механических, гидродинамических и гидроакустических воздействий, возникающих в пазах РПА в процессе обработки жидких сред с наличием твёрдых включений, могущих стать причиной замедления роста клеток или их гибели [10].

Аппаратурно-технологическая схема ферментационной установки с применением абсор- бера представлена на рис. 1. Установка включает в себя бункер 1, полезным объёмом 60 л, снабженный охлаждающей рубашкой 6. Внутри бункера располагается внутренний цилиндрический стакан Нижняя часть бункера посредством трубопровода соединена со всасывающим патрубком центробежного насоса 4. Напорный трубопровод соединен с входным патрубком корпуса абсорбера. Патрубок с противоположной стороны абсорбера соединён с трубопроводом, по которому газожидкостная смесь возвращается в бункер. Сам абсорбер 2 представляет собой цилиндрическую камеру, в донной части которой располагается пульсационный узел, представляющий собой три диска диаметром 210 мм и толщиной 5 мм, двух неподвижных статора и подвижного ротора. Каждый из дисков имеет по три ряда сквозных отверстий диаметром 3 мм, расположенных вдоль условных концентрических окружностей. Общее число отверстий - 160 шт.

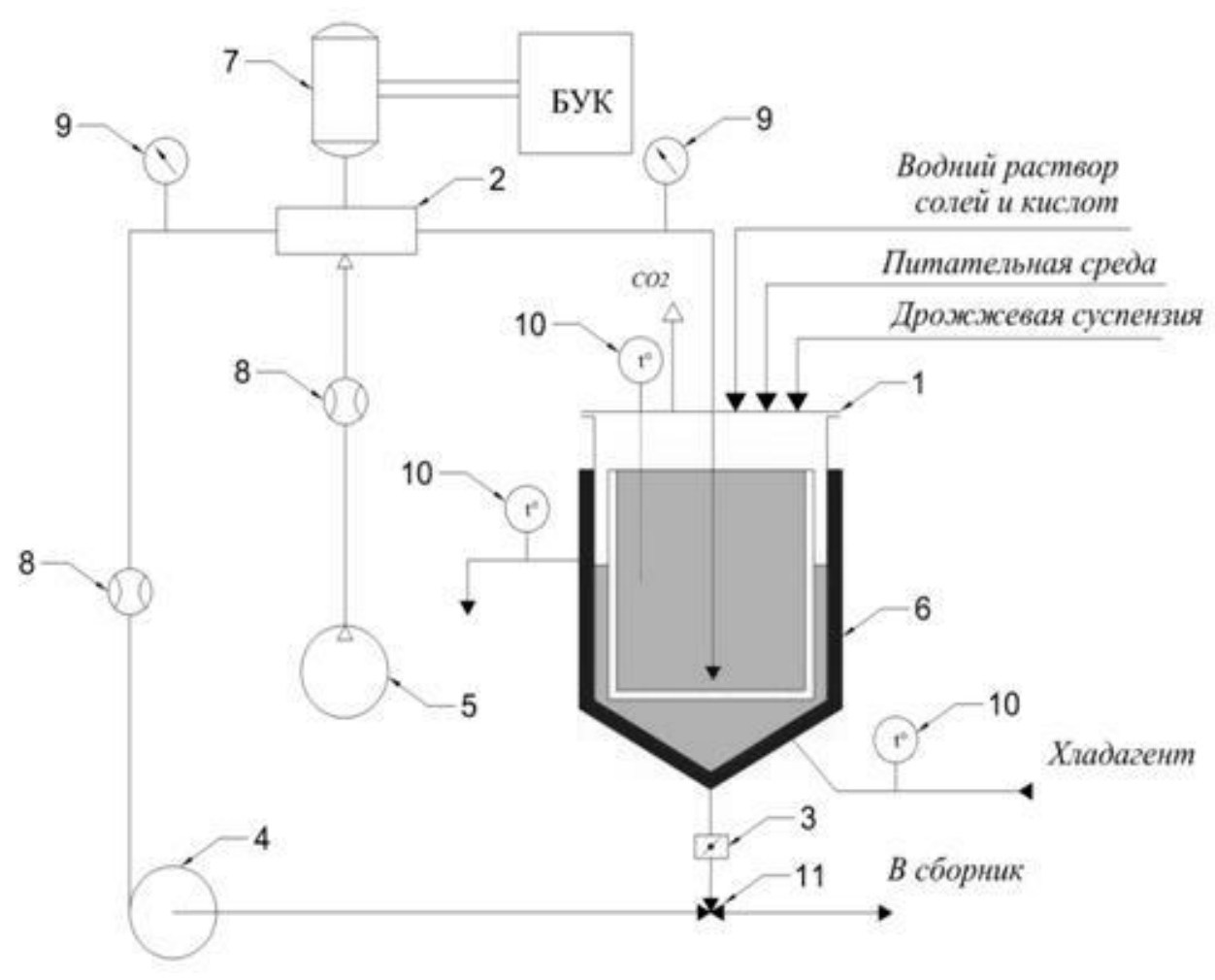

Рис. 1. Аппаратурно-технологическая схема тепломассообменной установки для культивирования микроорганизмов на абсорбере: 1 -бункер; 2 -абсорбер; 3 -заслонка;

4 -центробежный насос; 5 - компрессорная установка; 6 -рубашка охлаждения; 7 - электродвигатель; 8-расходомер; 9 -манометр; 10 - термомертр; 11 - трехходовой кран; БУК - блок управления и контроля. 
Воздух на аэрацию поступает в газовую камеру, расположенную под пульсационным узлом. Ротор вращается электродвигателем. Частота оборотов ротора регулируется изменением частоты вращения ведущего вала. Воздух поступает а абсорбер от компрессора. Установка снабжена контрольно-измерительной аппаратурой.

Сравнение эффективности установок с абсорбером и РПА в процессе аэрации культуральных жидкостей базируется на двух составляющих количестве накопленной биомассы за время культивирования, а значит скорости массопереноса кислорода, и потреблённой при этом мощности. Параметры работы оборудования подбирались таким образом, что бы обеспечить равенство скорости потока жидкости во входном патрубке РПА (абсорбера) и равенство объёма подаваемого в рабочую зону воздуха.

В ферментационной установка с РПА роторно-пульсационный аппарат совмещает в себе функцию аэратора и функцию насоса, обеспечивающего движение культуральной жидкости по контуру. В установке с абсорбером эти задачи выполняются разными устройствами. Для перекачивания жидкости был выбран насос КМ 50-32-125, обладающий сходными с РПА техническими характеристиками.

Технические характеристики насоса и РПА представлены в табл.1.

Таблица 1. Технические характеристики перекачивающих устройств ферментационных установок на базе абсорбера и на базе РПА

\begin{tabular}{|l|c|c|}
\hline & КМ 50-32-125 & РПА \\
\hline Объёмный расход, $\mathrm{M}^{3} / \mathrm{c}$ & 12,5 & 9 \\
\hline Напор, м в.ст. & 20 & 10 \\
\hline Потребляемая мощность, кВт & 2,2 & 3,0 \\
\hline
\end{tabular}

Вращательное движение ротора абсорбера обеспечивается электродвигателем мощностью 1,5 кВт.

Подача воздуха в абсорбер осуществляется с помощью компрессорной установки УК-40$2 \mathrm{M}$ (компрессор безмаслянный) с номиналь- ным рабочим давлением 2 кгс/см² (196 кПа), производительностью 34 л/мин $(0,6$ л/с). Максимальное давление 3,5 кгс/см² (343 кПа). Производительность 75 л/мин (1,25 л/с). Потребляемая мощность при номинальном напряжении (220 B, 50 Гц) и номинальном давлении 550 ВА (0,33 кВт).

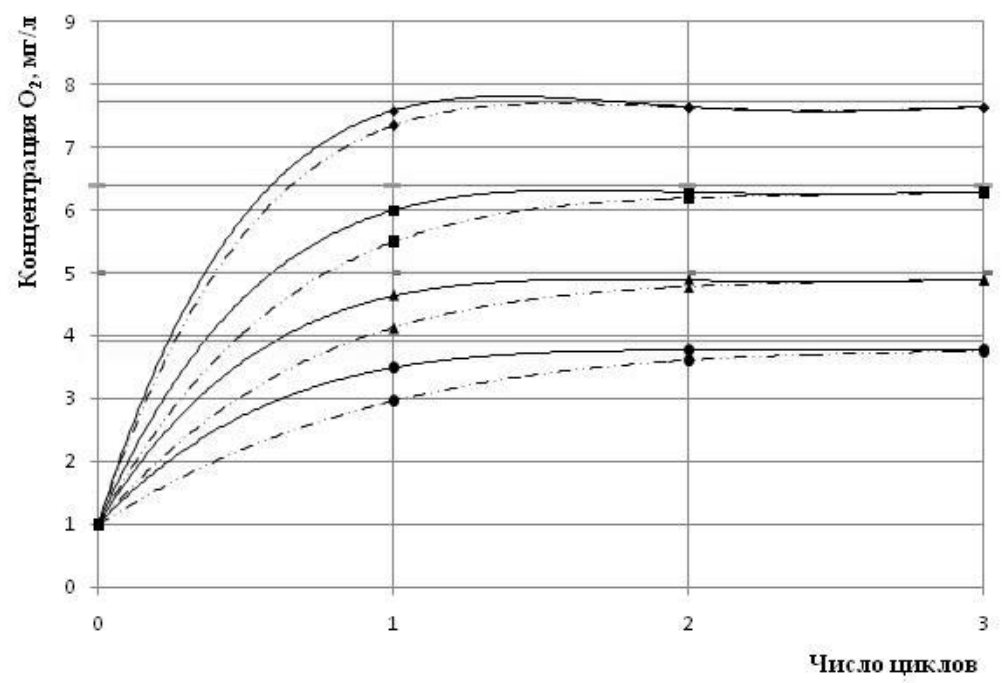

Рис. 2. Зависимость концентрации растворённого кислорода от количества циклов обработки при концентрации СВ: - вода; - 3 \%; $\triangle$ - $5 \%$; $-10 \%$.

Сплошная линия-установка с РПА, пунктирная-с абсорбером. 
Определение степени аэрации питательной и культуральной жидкости проводилось по методике, представленной в [2,3]. Оптимальные параметры работы РПА представлены в [11].

Зависимость концентрации растворённого кислорода от количества циклов обработки определялась на растворе мелассы с содержанием сухих веществ 10, 5 и $3 \%$. Объём жидкости составлял 30 л. Время одного цикла обработки составляло 15 с. Частота вращения роторного узла в РПА и ротора в абсорбере 47,75 об/с. Полученные результаты представлены на рис. 2 .

Полученные данные свидетельствуют о том, что при использовании абсорбера, кислород растворяется в среде на $25 \%$ медленнее, чем в РПА, таким образом, насыщение среды происходит не за два, а за три цикла обработки, что становится особенно важным при обработке бо́льших объёмов жидкости.

Дальнейшие исследования заключались в определении скорости массопереноса кислорода при культивировании дрожжей - сахароми- цетов на питательной среде с содержанием сухих веществ $10 \%$. Результаты представлены на рис. 2, как зависимость удельной скорости массопереноса кислорода от частоты вращения ротора.

Полученные данные свидетельствуют о том, что скорость растворения кислорода в установке с абсорбером ниже, чем в РПА. Однако, если в РПА при угловых скоростях вращения вала, бо́льших, чем 47,75 об./с скорость массопереноса условно уменьшается, что объясняется увеличением числа повреждённых клеток, то в установке с абсорбером рост клеток продолжается, а значит продолжается потребление кислорода [рис. 3].

Важным вопросом при обработке культуральных сред является физиологическое состояние дрожжей и количество погибших в процессе обработки клеток. Результаты сравнения числа повреждённых клеток за время культивирования в ферментационных установках с абсорбером и РПА в качестве аэрирующих устройств, представлены в таблице 2.

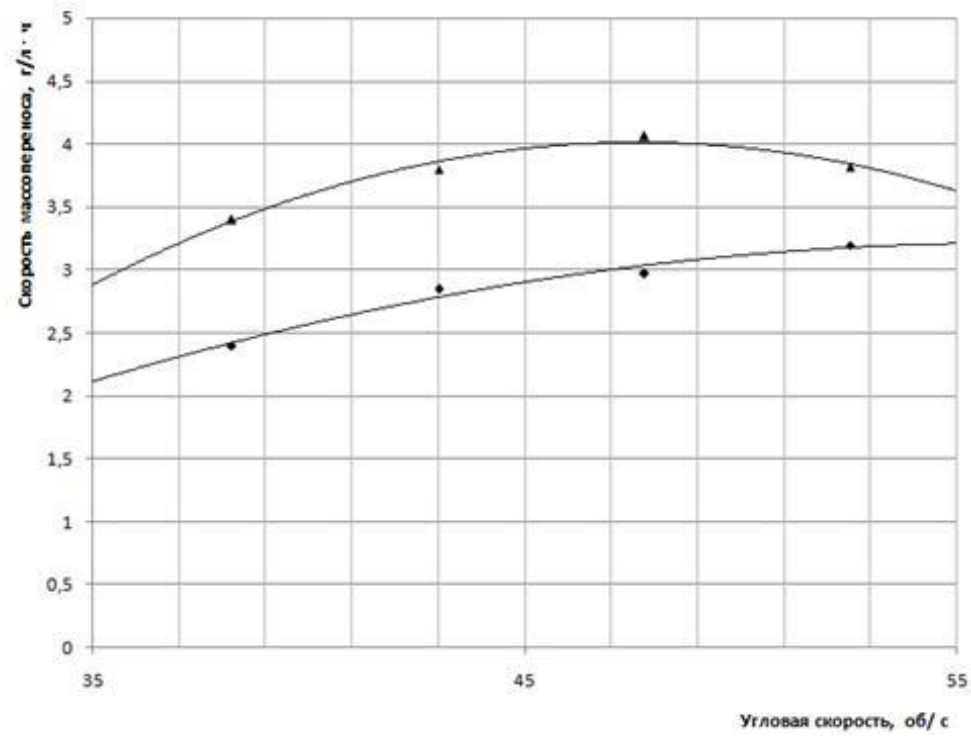

Рис. 3. Зависимость скорости массопереноса кислорода от угловой скорости вала при концентрации СВ $10 \%$ : -абсорбер; $\triangle$ - РПА.

Табл. 2. Количество повреждённых клеток за время культивирования в ферментационных установках с абсорбером и РПА

\begin{tabular}{|c|c|c|c|c|c|c|c|c|c|}
\hline \multirow{2}{*}{$\begin{array}{c}\text { Тип аэрирующего устройства } \\
\text { ферментационной установки }\end{array}$} & \multicolumn{7}{|c|}{ Время культивирования, час } \\
\cline { 2 - 12 } & 0 & 1 & 2 & 3 & 4 & 5 & 6 & 7 & 8 \\
\hline Абсорбер & 2 & 2 & 2 & 2 & 2 & 2 & 2 & 2 & 2 \\
\hline РПА & 2 & 2 & 2 & 3 & 3 & 3 & 4 & 4 & 5 \\
\hline
\end{tabular}


Полученные данные свидетельствуют о том, что обработка в абсорбере в исследуемом нами диапазоне угловых скоростей вращения ротора не оказывает отрицательного влияния на дрожжи, что является безусловным преимуществом данного аппарата, обработка же в аппарате с РПА приводит к появлению повреждённых клеток.
Основным параметром, определяющим эффективность установки, является расход энергии на проведение процесса. В таблице 3 представлены энергозатраты на производство килограмма дрожжевой биомассы в установке с РПА и установке с абсорбером соответственно.

Табл. 3. Энергетические затраты на производство дрожжевой биомассы

\begin{tabular}{|c|c|c|}
\hline \multirow{2}{*}{ Часовой прирост, кг/ч } & \multicolumn{2}{|c|}{ Удельные энергозатраты, кВт·час/кг } \\
\cline { 2 - 3 } & РПА & абсорбер \\
\hline 0,85 & 2,11 & 2,64 \\
\hline 1,09 & 2,29 & 2,87 \\
\hline 1,04 & 3,36 & 4,2 \\
\hline
\end{tabular}

\section{Выводы}

- проведено сравнение работы ферментационных установок с дискретно-импульсным вводом энергии, реализуемым в абсорбере и роторно-пульсационном аппарате в процессе выращивания дрожжей Saccharomyces cerevisiae;

- установлено, что в установке с РПА кислород растворяется на $20 \%$ быстрее, чем в установке с абсорбером;

- установлено, что при частотах оборотов роторов РПА и абсорбера до 47,75 об./с корость массопереноса кислорода в установке с РПА на $20 \%$ выше, чем в установке с абсорбером, однако, с увеличением частоты выше этого значения разница в скорости массопереноса кислорода снижается, что вызвано увеличением числа повреждённых клеток в установке с РПА, чего в установке с абсорбером не наблюдается;

- установлено, что энергозатраты на аэрацию культуральной жидкости при культивировании кормовых дрожжей в установке с абсорбером на 25 \% выше, чем в установке с РПА.

\section{ЛИТЕРАТУРА}

1. Микро- и наноуровневые прочессы в технологиях ДИВЭ: Тематический сборник статей / под общ. ред. А.А. Долинского - К.: Академпериодика, 2015. - 464 с.

2. Ободович А.Н. Исследование абсорбции кислорода воздуха в ферментационном аппарате с дискретно-импульсным вводом энергии / А.Н.
Ободович, А.Н. Фищенко, В.В. Сидоренко// Промышленная теплотехника. - 2016. - Т.38, № 2. c. $33-38$.

3. Ободович A.H. Влияние механизмов ДИВЭ на скорость массопереноса и рост микроорганизмов / А.Н. Ободович, А.Н. Фищенко, В.В. Сидоренко // Промышленная теплотехника. 2016. - T.38, № 1. - c. 25-30.

4. A.c. 787457 (СССР). Способ аэрирования жидкости при выращивании микроорганизмов / О.А. Кремнев, А.А. Долинский, А.А. Корчинский и др. - Опубл. в Б.И., 1980, №46.

5. А.c. 672155 (СССР). Способ насыщения жидкости газом / О.А. Кремнев, А.А. Долинский, А.А. Корчинский, Я.И. Коренберг. - Опубл. в Б. И., 1979, № 25.

6. А.с. 735290 (СССР). Устройство для импульсной аэрации жидкости / О.А. Кремнев, А.А. Долинский, А.А Корчинский и др. - Опубл. в Б. И., 1980, № 19.

7. Долинский A.A. Исследование влияния импульсно-дискретной подачи газа с частотой 1000...5000 Гц на процессы абсорбции / А.А. Долинский, А.А. Корчинский, В.В. Панчишин // Промышленная теплотехника. - 1983. - Т.5, № 3.c. $30-33$.

8. Бошенятов Б.В. Гидродинамика микропузырьковых газожидкостных сред. // Изв. Томск. политехн. ун-та. - 2005. - Т.308, №6. - С.161-164.

9. Долинский A.A. Энергосберегающие абсорбционные технологии в производстве газированных напитков / А.А. Долинский, Б.И. Басок, 
О.К. Шетанков, А.И. Чайка// Промышленная теплотехника. - 2001. - Т.23, № 4-5. - с. 137-140.

10.Грабова Т.Л. Диспергирование гетерогенных систем в роторно-пульсационных аппаратах дисково-цилиндрического типа: дис. кандидата техн. наук / Т. Л. Грабова. - К., 2007. - 124 с.
11.Ободович А.Н. Особенности гидродинамической обработки питательных сред в роторно-пульсационном аппарате / А.Н. Ободович, Т.Е. Мудрак, В.В. Сидоренко/ / Промышленная теплотехника. - 2016. - Т.38, № 3. - с. 22-28. 


\section{COMPARISON OF EFFECTIVENESS OF AERATION OF THE CULTURE MEDIUM IN THE MASS TRANSFER SETUPS WITH DISCRETE-PULSED INPUT OF ENERGY DURING CULTIVATION OF BAKERY YEAST}

\section{A. Dolinskiy, A. Obodovich , A. Fischenko, V. Sidorenko}

Institute of Engineering Thermophysics, National Academy of Sciences of Ukraine, Zhelyabova str., 2a, Kiev, 03680, Ukraine

Key words: method of discrete-pulse energy input, aeration, rotary pulsation apparatus, the absorber, the rate of mass transfer.

The article provides an overview of the scope of devices that implement the DPIE method for intensification of mass transfer processes in the system of gas - liquid. Mass transfer plants with RPA and absorber and their features and operating principle are considered. The results of comparison of plants during aeration culture media for growing yeast Saccharomyces cerevisiae are determined. The data on the solubility of oxygen, the mass flow rate and the number of damaged cells. The energy costs for production of yeast biomass for each plant are determined.

References 11, tables 3, figures 3.

1. Micro- and nano-tiered processes in DPIE technologies: Thematic collection of articles/ by edition A.Dolinskiy. - K.: Akademperodika, 2015. 464 p. [Rus].

2. Obodovich A.N. The study of atmospheric oxygen absorption in the fermentation unit with discrete-pulse energy input / A.N. Obodovich, A.N. Fischenko, V.V. Sidorenko // Promyishlennaya teplotehnika. - 2016. - vol. 38, №2 - p. 33-38 [Rus].

3. Obodovich A.N. Effect mechanisms of DPIE on mass transfer rate and the growth of microorganisms/ A. N. Obodovich, A.N. Fischenko, V.V. Sidorenko// Promyishlennaya teplotehnika. 2016. - vol. 38, №1 - p. 25-30 [Rus].

4. O.A. Kremnev, A.A. Dolinskiy, A.A. Korchinskiy et al. The process fluid aeration for growing microorganisms / Certificate of authorship USSR, no 787457, 1980 [Rus].

5. O.A. Kremnev, A.A. Dolinskiy, A.A. Korchinskiy, Ya.I. Korenberg. Method of saturation liquid with gas / Certificate of authorship USSR, no 672155,1979 [Rus].

6. O.A. Kremnev, A.A. Dolinskiy, A.A. Korchinskiy et al. Device for pulsed aeration of liquid / Certificate of authorship USSR, no735290, 1980 [Rus].

7. Dolinskiy A.A. Investigation of the effect of pulse-discrete gas supply with a frequency of $1000 \ldots 5000 \mathrm{~Hz}$ on the absorption process / A.A. Dolinskiy, A.A. Korchinskiy, V.V. Panchishin. Promyishlennaya teplotehnika. - 1983. - vol. 5, №3 p. 30-33. [Rus].

8. Boshenyatov B.V. Hydrodynamics of microbubbles of gas-liquid media / B.V. Boshenyatov. Izvestiya Tomskogo politehnicheskogo universiteta. - 2005. - vol. 308, №6 - p. 161-164. [Rus].

9. Dolinskiy A.A. Energy saving absorption technology in the production of carbonated beverages / A.A. Dolinskiy, B.I. Basok, O.K. Shetankov, A.I. Chayka. - Promyishlennaya teplotehnika. - 2001. - vol. 23, № 4-5. - p. 137-140 [Rus].

10.Grabova T. Dispersion of heterogeneous systems in a rotary-pulsation apparatus of disccylindrical type, $\mathrm{PhD}$ dissertation (Engineering). Institute of engineering thermophysics, 2007 [ Rus].

11. Obodovich A.N. Pecularities of hydrodynamic processing of the nutrient medium in the rotorpulsation apparatus/ A.N. Obodovich, T. E. Mudrak, V.V. Sidorenko . - Promyishlennaya teplotehnika. 2016. - vol. №3, p. 22-28 [Rus].

Получено 23.06.2016 Received 23.06.2016 